\title{
Safety in numbers? Supplanting data quality with fanciful models in wildlife monitoring and conservation
}

\author{
Guillermo Blanco · Fabrizio Sergio · José A. Sanchéz-Zapata • \\ Juan M. Pérez-García • Francisco Botella · Félix Martínez • \\ Iñigo Zuberogoitia • Oscar Frías · Federico Roviralta • \\ José E. Martínez • Fernando Hiraldo
}

\begin{abstract}
Ecologists and conservation biologists seem increasingly attracted to sophisticated modelling approaches, sometimes at the expense of attention to data quality and appropriateness of fieldwork design. This dissociation may lead to a loss of perspective promoting biological unrealities as conclusions, which may be used in conservation applications. We illustrate this concern by focusing on recent attempts to estimate population size of breeding birds at large scales without any explicit testing of the reliability of the predictions through comparison with direct counts. Disconnection of analysts from "nature" can lead to cases of biological unrealities such as that used here to illustrate such trends. To counter this risk, we encourage investment in well-rounded scientists or more collaborative, multi-disciplinary teams capable of integrating sophisticated analyses with in-depth knowledge of the natural history of their study subjects.
\end{abstract}

\section{G. Blanco (\&) · O. Frías}

Department of Evolutionary Ecology, National Museum of Natural History (CSIC), c/José Gutierrez Abascal 2, 28006 Madrid, Spain

e-mail: gblanco@mncn.csic.es

F. Sergio · F. Hiraldo

Department of Conservation Biology, Estación Biológica de Doñana (CSIC), c/Americo Vespucio s/n, 41092 Seville, Spain

\section{J. A. Sanchéz-Zapata · J. M. Pérez-García · F. Botella}

Department of Applied Biology, University Miguel Hernández, Ctra. Beniel Km 3.2, 33012 Orihuela, Alicante, Spain

F. Martínez · F. Roviralta

Sociedad para la Conservación de los Vertebrados, Avda. de los Pinos 17, 58B, 28914 Leganés, Madrid, Spain

\section{Zuberogoitia}

Estudios Medioambientales Icarus S.L., Pintor Sorolla 6, 18C, 26007 Logroño, La Rioja, Spain

J. E. Martínez

Departamento de Ecología e Hidrología, Universidad de Murcia, Campus de Espinardo, 30100 Espinardo, Murcia, Spain 
Keywords Biological unrealities · Data quality · Sophisticated modelling · Population size estimates

\section{Introduction}

Recent decades have seen an exponential increase in the employment of ever more sophisticated computational and remote sensing tools in wildlife monitoring and conservation biology. In many cases, studies exclusively target the calibration and proposal of new, increasingly complex, presumably improved, models. While this is clearly welcomed, the sophistication of the analytical techniques often overrides and overshadows the quality of the biological data being analyzed. As a consequence, concern is spreading among ecologists about the loss of perspective derived from a growing overemphasis on analytical techniques rather than conceptual content, data quality, or theory development (e.g. Doak and Mills 1994; Belovsky et al. 2004; Guthery 2008a). The problem, clearly and recurrently expressed by ecologists, is exacerbated in conservation biology by its need for reliable applications. Sound conservation approaches require not only robust analytical methods but, importantly, reliable datasets that can be trusted (Nichols and Williams 2006; Lindenmayer and Likens 2009). In practice, many studies employ data from multiple sources, often relying on amateur work, without a thorough understanding or critical evaluation of the influence of the background data quality, and its subsequent analytical transformation, on the research conclusions. This process promotes a frequent dissociation between the quality of the modelling and the quality of the data behind it, often generating biological unrealities as conclusions, which may be used to propose conservation measures.

There is a great need for good data in understanding population dynamics linked to population size as a strong predictor of wildlife extinction risk. In fact, huge efforts and funds are increasingly invested in multiple programs of diverse schemes, goals and reliability, focusing on spatial and temporal variations in abundance and distribution of wildlife, as a proxy to population status and trends (e.g. Pereira and Cooper 2006; Baillie et al. 2008). These programs typically involve simultaneous surveys of multiple common species, and often lack a previous comprehensive assessment of potential species-specific and scale-dependent sources of variation, bias and error (e.g. Pollock et al. 2002; Elphick 2008). In contrast, programs based on the monitoring of a single species are typically based on a more intensive effort to determine absolute population size for a particular region and are usually more limited in duration (i.e. number of years) because of logistic and funding constraints. Such intensive, single-species programs have often been directed at large endangered species, such as many avian top predators (Thompson 2004). These species are often elusive and typically occur at low density, which makes it difficult to determine their abundance through large-scale, amateur-based monitoring schemes simultaneously tracking multiple common species (e.g. Andersen 2007; Hardey et al. 2009).

Monitoring birds to estimate absolute abundance is often faced with multiple potential biases and errors during sampling (i.e. at the source of a study), which can magnify the error of outcome estimates when multiple assumptions are made, and strong inference and sophisticated calculations are used to quantify or extrapolate population properties at larger scales. Accordingly, a large body of research has focused on sampling designs and analytical procedures that allow more reliable extrapolation of modelling results to non-survey areas (e.g. Pollock et al. 2002; Elphick 2008). Oddly, much less effort has been devoted to 
validate survey schemes by comparing their statistical predictions with the 'true' abundance observed in the exact same area through more intensive monitoring. For instance, many recent attempts to estimate population size of breeding birds at large scales have applied increasingly sophisticated statistical frameworks, without any explicit testing of the reliability of their predictions through comparison with direct counts (e.g. Carrascal and Palomino 2008; Herrando et al. 2008; Sierdsema and Van Loon 2008). Here, we use a case study to illustrate how estimations based upon inference and statistical predictions can be highly artificial and misleading in certain cases. We then discuss the potential risks of loose application of attractive but assumption-rich analytical tools in conservation biology, unless these are accompanied by ad hoc comparisons with real data from control areas and proper calibration of potential errors and biases.

\section{A meaningful case study}

We illustrate the above concerns by focusing on a recent attempt to estimate population size of breeding forest raptors in Spain, based on volunteer fieldwork and sophisticated computational procedures including data standardization, modelling, extrapolation and resampling (hereafter “statistical estimation”, see Palomino and Valls 2011 for details). Data from these types of publications by national-level conservation NGOs are typically used by local administrations to establish conservation priorities and targets. We compared the results obtained from such statistical procedures with recent or current direct counts conducted by intensive searching for territories and nests (hereafter "direct counts"; see Table 1 for details), following the traditional approach to raptor surveys (Andersen 2007). In direct counts, the investigators typically search nests and territories until they are reasonably sure that all in the study area have been detected. With the goal of a complete census in mind, they usually adjust their search effort and procedures to the biological challenges imposed by each target species in each particular area. Thus, the rationale behind these sorts of intensive approaches is to reach an estimate of population abundance that is as close as possible to the real population size, as if effort was unlimited. Therefore, we consider the compiled case-studies as useful controls for testing the reliability of the statistically estimated population sizes.

The results of such comparisons indicated that the statistical approach predicted population sizes that largely over or underestimated the abundance obtained by direct counts in the exact same area. Statistical inference even created 'virtual' populations in areas where the species did not nest or did so extremely irregularly and in small numbers (Table 1). Most of the abundance estimates obtained by direct counts, and even their minimum and maximum values (i.e. even accounting for annual variations), did not fall within the range of the statistical estimates (90 \% confidence intervals). In some cases, statistical estimation and direct counts covered different, albeit very recent years. However, the temporal separation was never great enough to explain the differential population estimates. In most cases, such recoveries would have had to be unrealistically spectacular. This can be illustrated by the case of the red kite Milvus milvus population of Madrid, which showed a dramatic crash between the first national census in 1994 (65-70 pairs, Viñuela et al. 1999) and 2001 (36 pairs, SCV 2003), then remaining stable until the last national census of 2005 at 40 pairs (Cardiel 2006). Statistical estimation predicted an unlikely population explosion to 140 territories estimated for 2009-2010 (Table 1). This recovery is demographically unrealistic according to the estimated vital rates found in other populations (e.g. Tavecchia et al. 2011), unless assuming a massive immigration episode from other regions. The latter is highly unlikely given the typically high natal and breeding philopatry of this species 
Table 1 Comparison between direct counts and statistical estimations of the population size of breeding forest raptors in several provinces of Spain

\begin{tabular}{|c|c|c|c|c|c|}
\hline \multirow[t]{2}{*}{ Species } & \multirow[t]{2}{*}{ Province } & \multicolumn{2}{|c|}{ Number of territories } & \multirow[t]{2}{*}{ Error $(\%)^{\mathrm{a}}$} & \multirow[t]{2}{*}{ Accuracy (\%) } \\
\hline & & Direct count & Statistical estimation & & \\
\hline \multirow[t]{12}{*}{ Milvus milvus } & Madrid & $40^{\mathrm{c}}$ & $140(120-160)$ & $? 250$ & 28.6 \\
\hline & Alicante & $0^{\mathrm{d}}$ & $9(3-15)$ & - & 0.0 \\
\hline & Almeria & $0^{\mathrm{e}}$ & $3(0-6)$ & - & 0.0 \\
\hline & Cádiz & $2^{\mathrm{e}}$ & $24(14-33)$ & $? 1,100$ & 8.3 \\
\hline & Córdoba & $0^{\mathrm{e}}$ & $94(80-110)$ & - & 0.0 \\
\hline & Granada & $0^{\mathrm{e}}$ & $2(0-4)$ & - & 0.0 \\
\hline & Huelva & $49^{\mathrm{d}}$ & $100(80-120)$ & ?104 & 49.0 \\
\hline & Jaen & $0^{\mathrm{e}}$ & $59(45-74)$ & - & 0.0 \\
\hline & Málaga & $0^{\mathrm{e}}$ & $16(9-24)$ & - & 0.0 \\
\hline & Sevilla & $1^{\mathrm{e}}$ & $200(190-220)$ & ?19,900 & 0.5 \\
\hline & Bizkaia & $1(0-1)^{\mathrm{d}}$ & 0 & -100 & 0.0 \\
\hline & Murcia & $0^{\mathrm{d}}$ & $19(10-28)$ & - & 0.0 \\
\hline Milvus migrans & Alicante & $0(0-1)^{\mathrm{d}}$ & $11(5-17)$ & - & 0.0 \\
\hline \multirow[t]{3}{*}{ Circaetus gallicus } & Madrid & $54(45-63)^{d}$ & $120(100-140)$ & ?122 & 45.0 \\
\hline & Alicante & $41(36-49)^{d}$ & $130(110-140)$ & ?217 & 31.5 \\
\hline & Bizkaia & $4^{\mathrm{d}}$ & $21(12-30)$ & ?425 & 19.0 \\
\hline \multirow[t]{2}{*}{ Pernis apivorus } & Madrid & $45(42-48)^{d}$ & $9(4-14)$ & -400 & 20.0 \\
\hline & Murcia & $0^{\mathrm{d}}$ & $8(5-14)$ & - & 0.0 \\
\hline \multirow[t]{3}{*}{ Accipiter gentilis } & Alicante & $28(21-35)^{d}$ & $55(42-66)$ & ?96 & 50.9 \\
\hline & Bizkaia & $15^{\mathrm{d}}$ & 77(63-91) & ?413 & 19.5 \\
\hline & Murcia & $14^{\mathrm{d}}$ & 91(73-110) & ?550 & 15.4 \\
\hline Buteo buteo & Alicante & $60(54-75)^{d}$ & $280(250-310)$ & ?367 & 21.4 \\
\hline \multirow[t]{2}{*}{ Hieraaetus pennatus } & Alicante & $1(0-4)^{d}$ & 150(130-160) & $? 14,900$ & 0.7 \\
\hline & Bizkaia & $9^{\mathrm{d}}$ & $15(8-22)$ & ?66 & 60 \\
\hline
\end{tabular}

"Error" indicates the percentage difference between the 'real' (direct count) and predicted (statistical estimation) absolute number of territories. The sign ? or - indicates whether the statistical estimation over or underestimated the population size obtained by direct counts. "Accuracy" indicates the difference between the 'real' (direct count) and the estimated (statistical) number of pairs in relative terms

${ }^{a}$ Calculated as: [(direct count - statistical estimate)/direct count] 9100

${ }^{\mathrm{b}}$ Calculated as: direct count 9 100/statistical estimate

c Data from Cardiel (2006), on the basis of previous censuses (Viñuela et al. 1999; SCV 2003)

d Own data. Honey buzzard in Madrid in 2010 (based on previous annual census since 2004, Roviralta et al. 2004), short-toed eagle (census between 2005 and 2010 in Madrid Province), several species in Bizkaia in 2010 (based on previous annual censuses since 1997, Zuberogoitia et al. 2011), several species in Alicante in 2009 (based on previous censuses since 2007), several species in Murcia in 2009-2010 (based on previous censuses since 2007), and red kites in Doñana National Park, Huelva (2006), complemented with data from other areas (2010) recorded by the Consejería de Medio Ambiente of the Junta de Andalucía (provided by J. R. Benitez and R. Arenas). Variation (in parentheses) indicates different counts between years (2009-2011) in Alicante and Bizkaia, and the range between the minimum confirmed number of pairs to the maximum possible (confirmed plus probable) number of pairs in Madrid

e Data from Consejería de Medio Ambiente of the Junta de Andalucía based on direct counts in 2010 (provided by J. R. Benitez and R. Arenas) 
(Newton et al. 1994), its poor conservation status and its steep negative trends in surrounding and more distant areas (Cardiel 2006).

Clearly, the above-cited macroscopic and systematic differences between statistical estimation and direct counts point to substantial sources of error at some stage of the fieldwork and modelling process, or both. Collection of data in the field, their validation, and statistical assumptions, analysis and inference are all subject to multiple sources of bias and uncertainty that may compromise the reliability of population estimates calculated by statistical extrapolation. Unfortunately, it is often impossible to determine a posteriori what uncontrolled biases and errors operated in the process yielding the statistical estimation. In our case study, we believe that major sources of error and bias arose from survey design and fieldwork methodology, coupled with an inadequate spatial coverage of the sampled areas, given the final goal of extrapolation to very large areas. Further biases arose due to the fact that elusive species, such as many forest raptors, were not searched by ad hoc species-specific methods and dates, but rather using generalised methods that were applied homogeneously to all species. This is peculiar because, with few exceptions, an experienced surveyor would likely employ profoundly different search strategies and target different periods, sites, altitudes and habitats when looking for each species (Hardey et al. 2009). Finally, further errors could have arisen later in the analytical stage. For example, environmental variables were subjectively categorized without a particular species in mind or lacking clear biological reasoning in the statistical estimation. Thus, certain habitatclasses (e.g. the pooling of riparian and oak woodlands, or young and mature forest) may or may not have represented biologically relevant environmental features for the target species, and their consideration in large-scale population size estimation through extrapolation by habitat may promote significant biases (e.g. Harris and Haskell 2007). Therefore, multiple errors and biases could have arisen at several stages, from methodological field biases, to scale problems and analytical inadequacies. The unknown interaction and likely amplification of sequential sources of error throughout the modelling process likely contributed to the gross final errors of estimation, well exemplified by the prediction of species occurrence in large areas from which such species have long been absent with reliable certainty.

The risk of statistical ritualization

Multiple potential biases and errors linked to field design and implementation frequently become magnified at later stages through further uncertainties associated with statistical assumptions, strong inference and sophisticated sequential equations each carrying its own intrinsic errors. More frequently than commonly realized, this process may result in unrealistic estimations and predictions (Guthery 2008a). Thus, while the use of up-to-date statistics and mathematics is obviously useful, we are concerned that many researchers may be currently more interested in sophisticated modelling procedures at the expense of attention to data quality and appropriateness of fieldwork design. This overemphasis on computationally-rich approaches may result in the blurring of the biologically-useful information of a dataset by replacing it with a dearth of quantitative algorithms of complex interpretation and problematic extrapolation to non-sampled areas. In extreme cases, such overemphasis on analytical methods and their dissociation from fieldwork may end up converting the entire modelling process to nothing more than an exercise in formally structured guesswork. This leads to the paradox of many methodological papers focusing on analytical approaches proposed for conservation, but presented through an example that ends up being a guide to how you should NOT use those models. Such a vicious cycle is 
reinforced by the common perception that complex analytical procedures and presentation of convoluted equations and models are synonymous with scientific objectivity and rigour (Murtaugh 2007; Guthery 2008b). For instance, the confidence intervals of mean population sizes of the statistical estimations in our case study, calculated through bootstrapping re-sampling, were considered to add a high degree of statistical certainty to the predictions (Palomino and Valls 2011). Unfortunately, even though the term "confidence interval" would suggest reliable conclusions, it does not take into account biases in fieldwork design and model assumptions (Elphick 2008).

The end result of this current overemphasis on fashionable complex models is a multitude of analyses that look methodologically appealing but possess little biological content or utility. This kind of formally attractive but conceptually misleading computational routine has been accused of halting progress in general and applied ecology (Belovsky et al. 2004; Guthery 2008b), as a form of ritualistic by-product of human predisposition to orthodoxy and tribalism (Wilson 2004; Guthery 2008a).

\section{Implications for conservation}

Current red lists of conservation status assign risk categories on the basis of criteria heavily based on population size, temporal trends, and geographic range size. Therefore, assigning species to risk categories through erroneous or non-validated estimates of abundance and other population traits (e.g. current and future potential distributions, see Araújo et al. 2011) could lead to serious misinformed decisions in conservation management and investment aimed at improving scarce populations of imperilled species. Thus, the status of some threatened species could radically change in their assigned IUCN categories depending on whether computational forecasts or real data (i.e. direct counts) are considered. We stress that we are absolutely not against the utilization of indirect methods to hypothesize absolute abundance and other traits in wildlife populations. However, we express serious concerns over the growing emphasis on loose utilization of these methods to establish population sizes and other traits with implications in conservation management. As demonstrated by our case study, sophisticated forecasts are not exclusive to specialized academic exercises, and increasingly permeate the sector of conservation biologists and wildlife managers, such as conservation-based NGOs. In such contexts, complex models may be perceived even more as "holy grails" accepted as scientifically objective with little critical assessment. Conservation status assignment should be especially cautious in those cases in which no attempt has been made to validate the quantitative predictions with real data from systematic direct counts.

The imperative need for validation

Despite the enormous amount of effort and funds expended in population monitoring for conservation, there is considerable controversy over the validity of artificial population size estimates predicted through sampling and inference from statistical procedures (Newson et al. 2005; Murgui 2011; Norman et al. 2011). Part of the controversy arises because the increasing complexity of the analytical procedures prevents a full understanding of how the predictions of population size were obtained, often generating mistrust of the unknown. In other cases, these estimates are considered fully unrealistic by experienced observers with indepth knowledge of particular areas and species. This usually results in conflict and dissatisfaction among funding agencies and the volunteers that provide invaluable help and huge amounts of useful raw data on particular species in particular areas (Greenwood 2007). 
Despite the diffuse concerns over the reliability of population estimates derived from computational frameworks, ironically, it is rarely possible to demonstrate their inaccuracies. This is usually because the very large scale over which inference and extrapolation are typically applied precludes a critical assessment through comparison with direct counts conducted over the same area. In this scenario, validation of the estimates in smaller-scale calibration areas becomes an even more essential requirement. In its absence, large-scale estimates should be presented as a fundamentally hypothetical exercise, and should be thus considered by managers, government agencies and international conservation institutions.

Further debate, tangentially important to this note, is currently focused on the scale at which population size should be assessed for the purpose of global or regional conservation of each species. Obviously, direct counts of many abundant and widely distributed species can not be conducted over very large areas. In these cases, a well-designed monitoring program should ensure that the relative or absolute abundance of common species is estimated as intensively and accurately as possible in ad hoc control areas. To this aim, we reiterate that monitoring programs recording abundance or population size should always include detailed species-specific pilot studies that allow the assessment and calibration of potential errors. This evaluation should imperatively incorporate the comparison of predicted population size with the real population size.

In conclusion, some ecologists and conservation biologists seem increasingly attracted to sophisticated modelling approaches. While more powerful computational tools can allow deeper insight into ecological systems, they also come with assumptions and caveats that should not be discounted. Among the most notable of these is the fact that powerful analytical tools should be accompanied by powerful data, although even 'weak' analytical tools would produce inappropriate conclusions if the assumptions of those tools were violated and fundamental model validation techniques had been ignored. Emphasis on sophisticated modelling approaches is exponentially increasing, but attention to data quality and appropriateness of fieldwork design seems to be alarmingly declining. Such disconnections of analysts from "nature" will very likely lead to increasing cases of biological unrealities like that used here to illustrate such trends. To counter such risks, we encourage investment in well-rounded scientists or more collaborative, multi-disciplinary teams capable of integrating sophisticated analyses with indepth knowledge of the natural history of their study subjects (Futuyma 1998; Dayton 2003; Greene 2005). In parallel, we hope to see major improvements in the design of large-scale field surveys, with incorporation of spatio-temporally replicated calibration (for models) and validation (for results). We recognize the logistical difficulties imposed by such approaches, but we also consider that these would be overridden by the benefits acquired by more transparent and valid procedures. These seem essential for a knowledge-based society urged to understand and preserve a nature in crisis.

\section{References}

Andersen DE (2007) Survey techniques. In: Bird DM, Bildstein KL (eds) Raptor research and management techniques. Hancock House Publishers, Blaine, pp 89-100

Araújo MB, Guilhaumon F, Neto DR, Pozo I, Calmaestra R (2011). Impactos, vulnerabilidad y adaptación al cambio climático de la biodiversidad española. 2 Fauna de vertebrados. Dirección General de Medio Natural y Política Forestal. Ministerio de Medio Ambiente, y Medio Rural y Marino, Madrid, p 640. http://www.ibiochange.mncn.csic.es/atlascc/. Accessed 26 Dec 2011

Baillie JEM, Collen B, Amin R, Akcakaya HRA, Butchart SHM, Brummitt N, Meagher TR, Ram M, HiltonTaylor C, Mace GM (2008) Towards monitoring global biodiversity. Conserv Lett. doi:10.1111/j.1755263X.2008.00009.x 
Belovsky GE, Botkin DB, Crowl TA, Cummins KW, Franklin JF, Hunter MLJ, Joern A, Lindenmayer DB, Macmahon JA, Margules CR, Scott JM (2004) Ten suggestions to strengthen the science of ecology. Bioscience 54:345-351

Cardiel I (2006) El Milano Real en España. II censo nacional. SEO/BirdLife, Madrid

Carrascal L, Palomino D (2008) Las aves comunes reproductoras en España. Población en 2004-2006. SEO/ BirdLife, Madrid

Dayton P (2003) The importance of the natural sciences to conservation. Am Nat 162:1-13

Doak DF, Mills LS (1994) A useful role for theory in conservation. Ecology 75:615-626

Elphick CS (2008) How you count counts: the importance of methods research in applied ecology. J Appl Ecol 45:1313-1320

Futuyma D (1998) Wherefore and whither the naturalist? Am Nat 151:1-6

Greene HW (2005) Organisms in nature as a central focus for biology. Trends Ecol Evol 20:23-27

Greenwood JJD (2007) Citizens, science and bird conservation. J Ornithol 148:77-124

Guthery FS (2008a) A primer on natural resource science. Texas University Press, College Station

Guthery FS (2008b) Statistical ritual versus knowledge accrual in wildlife science. J Wildl Manag 72:1872-1875

Hardey J, Crick H, Wernham C, Riley H, Etheridge B, Thompson D (2009) Raptors: a field guide to surveys and monitoring. The Stationery Office, Edinburgh

Harris JBC, Haskell DG (2007). Land cover sampling biases associated with roadside bird surveys. Avian Conserv Ecol 2(2):12. http://www.ace-eco.org/vol2/iss2/art12/. Accessed 15 Feb 2012

Herrando S, Brotons L, Estrada J, Pedrocchi V (2008) The catalan common bird survey (SOCC): a tool to estimate species population numbers. Revista Catalana d Ornitologia 24:138-146

Lindenmayer DB, Likens GE (2009) Adaptive monitoring: a new paradigm for long-term research and monitoring. Trends Ecol Evol 24:482-486

Murgui E (2011) How many common breeding birds are there in Spain? A comparison of census methods and national population size estimates. Ardeola 58:343-364

Murtaugh PA (2007) Simplicity and complexity in ecological data analysis. Ecology 88:56-62

Newson SE, Woodburn RJW, Noble DG, Baillie SR, Gregory RD (2005) Evaluating the breeding bird survey for producing national population size and density estimates. Bird Study 52:42-54

Newton I, Davies PE, Moss D (1994) Philopatry and population growth of red kites Milvus milvus, in Wales. Proc R Soc B 257:317-323

Nichols JD, Williams BK (2006) Monitoring for conservation. Trends Ecol Evol 21:668-673

Norman D, Harris RJ, Newson SE (2011) Producing regional estimates of population size for common and widespread breeding birds from national monitoring data. Bird Study. doi:10.1080/00063657.2011. 623766

Palomino D,Valls J (2011) Las rapaces forestales en España. Población reproductora en 2009-2010 y método de censo. SEO/BirdLife, Madrid. http://www.seo.org/media/docs/36mono.pdf. Accessed 16 Aug 2011

Pereira HM, Cooper HD (2006) Towards the global monitoring of biodiversity change. Trends Ecol Evol 21:123-129

Pollock KH, Nichols JD, Simonst TR, Farnsworth GL, Bailey L, Sauer JR (2002) Large scale wildlife monitoring studies: statistical methods for design and analysis. Environmetrics 13:105-119

Roviralta F, Tello J, Alcobendas G, Lopez-Septiem JL Traverso JM, Pontón Ó (2004) Censo de abejero europeo (Pernis apivorus) en la Comunidad de Madrid, 2003. Anuario Ornitológico de Madrid 2003, p 86-93

SCV (2003) Censo de parejas reproductoras de milano real (Milvus milvus) en la Comunidad de Madrid, año 2001. http://es.geocities.com/scv_conservacion/milanoreal/milanoreal.html. Accessed 16 Dec 2011

Sierdsema H, Van Loon EE (2008) Filling the gaps: using count survey data to predict density distribution patterns and estimate population sizes. Revista Catalana d Ornitologia 24:88-99

Tavecchia G, Adrover J, Muñoz Navarro A, Pradel R (2011) Modelling mortality causes in longitudinal data in the presence of tag loss: application to raptor poisoning and electrocution. $\mathrm{J}$ Appl Ecol. doi: 10.1111/j.1365-2664.2011.02074.x

Thompson WL (2004) Sampling rare and elusive species. Island Press, Washington

Viñuela J, Martí R, Ruiz A (1999) El Milano Real en España, Monografía n86. SEO/BirdLife, Madrid Wilson EO (2004) On human nature. Harvard University Press, Cambridge

Zuberogoitia I, Castillo I, Zabala J, Iraeta A, Azkona A (2011) Population trends of diurnal forest raptors in Biscay. In: Zuberogoitia I, Martínez JE (eds) Ecology and conservation of european forest-dwelling raptors. Diputación Foral de Bizkaia, Bilbao, pp 70-80 